\title{
Improved motor development and good long-term glycaemic control with sulfonylurea treatment in a patient with the syndrome of intermediate developmental delay, early-onset generalised epilepsy and neonatal diabetes associated with the V59M mutation in the KCNJ11 gene
}

\author{
A. S. Slingerland $\cdot$ R. Nuboer • M. Hadders-Algra • \\ A. T. Hattersley • G. J. Bruining \\ Received: 25 April 2006 / Accepted: 11 July 2006 / Published online: 19 September 2006 \\ (C) Springer-Verlag 2006
}

\begin{abstract}
Aims/hypothesis Activating mutations in the KCNJ11 gene encoding the Kir6.2 subunit of the $\mathrm{K}_{\mathrm{ATP}}$ channels in pancreatic beta cells are a common cause of neonatal diabetes. One-third of patients also have developmental delay, which probably results from mutated $\mathrm{K}_{\mathrm{ATP}}$ channels in muscle, nerve and brain. Sulfonylureas, which bind to the sulfonylurea receptor 1 subunit of the $\mathrm{K}_{\mathrm{ATP}}$ channel, can replace insulin injections in patients with KCNJ11 mutations. The aim of this study was to investigate the long-term outcome and impact on neurological features of sulfonylurea treatment.
\end{abstract}

A. S. Slingerland and R. Nuboer contributed equally to this study.

A. S. Slingerland $\cdot$ A. T. Hattersley

Institute of Biomedical and Clinical Sciences,

Peninsula Medical School,

Exeter, UK

A. S. Slingerland

Department of Cardiology, Leiden University Medical Center,

Leiden, the Netherlands

R. Nuboer

Department of Paediatrics, Meander Medical Center,

Amersfoort, the Netherlands

M. Hadders-Algra

Department of Neurology (Developmental Neurology),

University Medical Center Groningen, University Groningen,

Groningen, the Netherlands

G. J. Bruining $(\bowtie)$

Division of Diabetes, KSP 1541, Erasmus University

Medical Center, Sophia Children's Hospital,

Dr Molenwaterplein 60,

3015 GJ Rotterdam, the Netherlands

e-mail: bruiningha@xs4all.nl
Methods We report the response to sulfonylurea treatment in a boy with neonatal diabetes and marked developmental delay resulting from the KCNJ11 mutation V59M.

Results Glibenclamide (glyburide) treatment was started at 23 months and resulted in insulin being discontinued, lower overall glycaemia, reduced glucose fluctuations and reduced hypoglycaemia. Good control $\left(\mathrm{HbA}_{1 \mathrm{c}} 6.5 \%\right)$ was maintained 2 years after discontinuing insulin, despite a reduction in the glibenclamide dose (from 0.41 to $0.11 \mathrm{mg} \cdot \mathrm{kg}^{-1} \cdot \mathrm{day}^{-1}$ ). Within 1 month of starting glibenclamide there was marked improvement in motor function, resulting in the patient progressing from being unable to stand unaided to walking independently, but there was no improvement in mental function.

Conclusions/interpretation This 2-year follow-up of a patient highlights that sulfonylurea treatment can result in prolonged, excellent glycaemic control and may improve motor features, but not mental features, associated with KCNJ11 mutations. This suggests that the neurological actions of sulfonylurea are initially principally on peripheral (nerve or muscle) rather than on central (brain) $\mathrm{K}_{\text {АTP }}$ channels. Early molecular diagnosis is important in patients with neonatal diabetes and neurological features.

Keywords Developmental delay - Glibenclamide . Glyburide $\cdot \mathrm{KCNJ11} \cdot \mathrm{Kir} 6.2 \cdot$ Neonatal diabetes .

Neurological features $\cdot$ Sulfonylurea $\cdot$ Sulphonylurea $\cdot$ V59M
Abbreviations
BSID Bayley Scales of Infant Development
DEND developmental delay early-onset generalised epilepsy and neonatal diabetes
SDS standard deviation scores
SUR sulfonylurea receptor 


\section{Introduction}

Activating mutations in the KCNJ11 gene encoding the Kir6.2 subunit of the $\mathrm{K}_{\text {ATP }}$ channels were recently described as a common cause of neonatal diabetes [1] The mutated $\mathrm{K}_{\mathrm{ATP}}$ channels show reduced closure in the presence of ATP, resulting in hyperpolarisation of the cell membrane and hence, in the pancreatic beta cell, in inhibition of insulin secretion. The majority of patients have permanent neonatal diabetes mellitus but transient neonatal diabetes mellitus has also been described [2]. Onethird of patients also have neurological features arising from mutated $\mathrm{K}_{\mathrm{ATP}}$ channels in muscle, nerve and brain [1, 3]. The most severe manifestation has been described as DEND syndrome (developmental delay, early-onset generalised epilepsy and neonatal diabetes) [3, 4]. A more common, but less severe presentation is intermediate DEND syndrome, when patients do not have epilepsy; in most cases this is associated with the V59M mutation [4]. The developmental delay includes muscle weakness, a delay in motor function and learning difficulties [1].

Diagnosis of a KCNJ11 mutation may have a major impact on treatment. Sulfonylureas close the $\mathrm{K}_{\mathrm{ATP}}$ channel by binding to the sulfonylurea receptor (SUR) 1 subunit [5]. This has meant patients previously dependent on insulin injections can now be treated with sulfonylurea tablets [6-10]. Long-term outcome is uncertain, as the longest follow-up reported to date is 6 months [6]. The mutations associated with a neurological phenotype tend to have the most severe functional deficit and respond less well to tolbutamide in vitro [11]. The impact on neurological features was not reported in the single patient with a V59M mutation who was transferred to sulfonylurea [6]. We report the long-term glycaemic response and impact on neurological features of sulfonylurea in a patient with the V59M mutation.

\section{Patient and report}

Case history A male infant was born with a low birthweight $(2,700 \mathrm{~g}$ P1.4 $)$ at 41 weeks of gestation after an unremarkable pregnancy and normal delivery to a highly educated Ethiopian couple who had emigrated to the Netherlands 7 years earlier. No dysmorphic features were noted and his head circumference was normal $(35 \mathrm{~cm},-0.16$ standard deviation score [SDS]). Blood glucose levels were normal $1-3 \mathrm{~h}$ postnatally (4.3 and $4.6 \mathrm{mmol} / \mathrm{l})$. There was no family history of diabetes.

Diabetes prior to switching to oral sulfonylurea at 6 weeks before his second birthday At 5 weeks, he presented with pyrexia, polydypsia, glucosuria and severe hyperglycaemia (35.1 $\mathrm{mmol} / \mathrm{l}$ ) but no ketoacidosis. C-peptide was just detectable $(250 \mathrm{pmol} / \mathrm{l})$ and islet cell autoantibodies to
GAD65, insulinoma-associated antigen-2 and insulin were absent. He was immediately treated with multiple insulin injections and subsequently followed the median Dutch postnatal growth curves (0 SDS or P50). There were no features of known syndromes of neonatal diabetes, the $G C K$ gene was normal on DNA sequencing and there was no imprinting abnormality on $6 q 24$ [3]. Because blood glucose values fluctuated greatly, he was switched to an insulin pump at 2 months. Even on the pump there were still problems, with marked hyperglycaemia and nocturnal hypoglycaemia. Aged 18 months, 72-h Minimed continuous subcutaneous glucose monitoring found blood glucose $\leq 2.2 \mathrm{mmol} / 1$ from 01.00 to $08.30 \mathrm{~h}$ on two subsequent nights.

Motor function, mental development and neurology prior to switching to oral sulfonylurea at 6 weeks before his second birthday At 9 months, a delay in motor milestones was noticed: he was not able to roll over, which normally developing infants achieve at 8 months at the latest [12]. At 12 months his milestones resembled that of a normally developing child aged 6-8 months: he was just able to sit without support, only used palmar and radial palmar grasps to get hold of objects and his language was a monosyllabic babble. No specific neurological features were noted and his EEG was normal. On the Bayley Scales of Infant Development (BSID) II he scored lower than the lowest detectable value of 55 or -3 SDS on both the Psychomotor Developmental Index and the Mental Developmental Index. He received supportive physiotherapy, speech therapy and special educational support but showed little improvement.

At 23 months he was still unable to stand unaided, his Psychomotor Development Index was equivalent to that of a normal 8-month child, and his Mental Development Index was equivalent to that of a 14-month child. Examination by a paediatric neurologist revealed muscle weakness and proximal hypotonia, especially in the lower limbs. Reflexes and sensation appeared normal and a CT scan of the legs showed no muscle atrophy. In addition, his spontaneous motor behaviour was characterised by a limited variation. His EEG was normal and there were no seizures.

The impact of sulfonylurea treatment on diabetes At 20 months of age, he was diagnosed with a V59M mutation in the KCNJ11 gene encoding the Kir6.2 subunit of the potassium channel, as previously reported (case ISPAD 55) [1]. The potential to respond to sulfonylurea therapy was suggested by plasma insulin increasing $12.8 \mathrm{pmol} / \mathrm{l}$ when he received $3 \mathrm{mg} / \mathrm{kg}$ tolbutamide i.v. despite only a $1.3 \mathrm{pmol} / 1$ increase with $0.3 \mathrm{~g} / \mathrm{kg} 20 \%$ glucose [1].

At 23 months, the child was put on the oral sulfonylurea glibenclamide (known as glyburide in the US and Canada), initially at low doses $\left(0.025 \mathrm{mg} \cdot \mathrm{kg}^{-1} \cdot \mathrm{day}^{-1}\right)$, in addition to 
insulin (Fig. 1). Low doses were used initially as the response to sulfonylureas was unknown. Glibenclamide doses were gradually increased and insulin doses, still given by insulin pump, could be reduced (Fig. 1). After 6 months of treatment he had come off insulin completely, using $0.41 \mathrm{mg} \cdot \mathrm{kg}^{-1} \cdot \mathrm{day}^{-1}$ of glibenclamide taken in two equal doses without any side effects. Glycaemic control improved as the sulfonylurea dose was increased, with reduced pre-meal glucose values and reduced fluctuation between minimum and maximum daily glucose values (Fig. 1). Interestingly, glucose values before lunch and dinner reduced $51 \%$ (mean 10.7 to $5.2 \mathrm{mmol} / \mathrm{l}$ ) and $37 \%$ (11.1 to $7.0 \mathrm{mmol} / \mathrm{l}$ ) respectively, whereas before breakfast, after an overnight fast, glucose values only reduced 5\% (7.4 to $7.0 \mathrm{mmol} / \mathrm{l}) . \mathrm{HbA}_{1 \mathrm{c}}$ values reduced after insulin had been
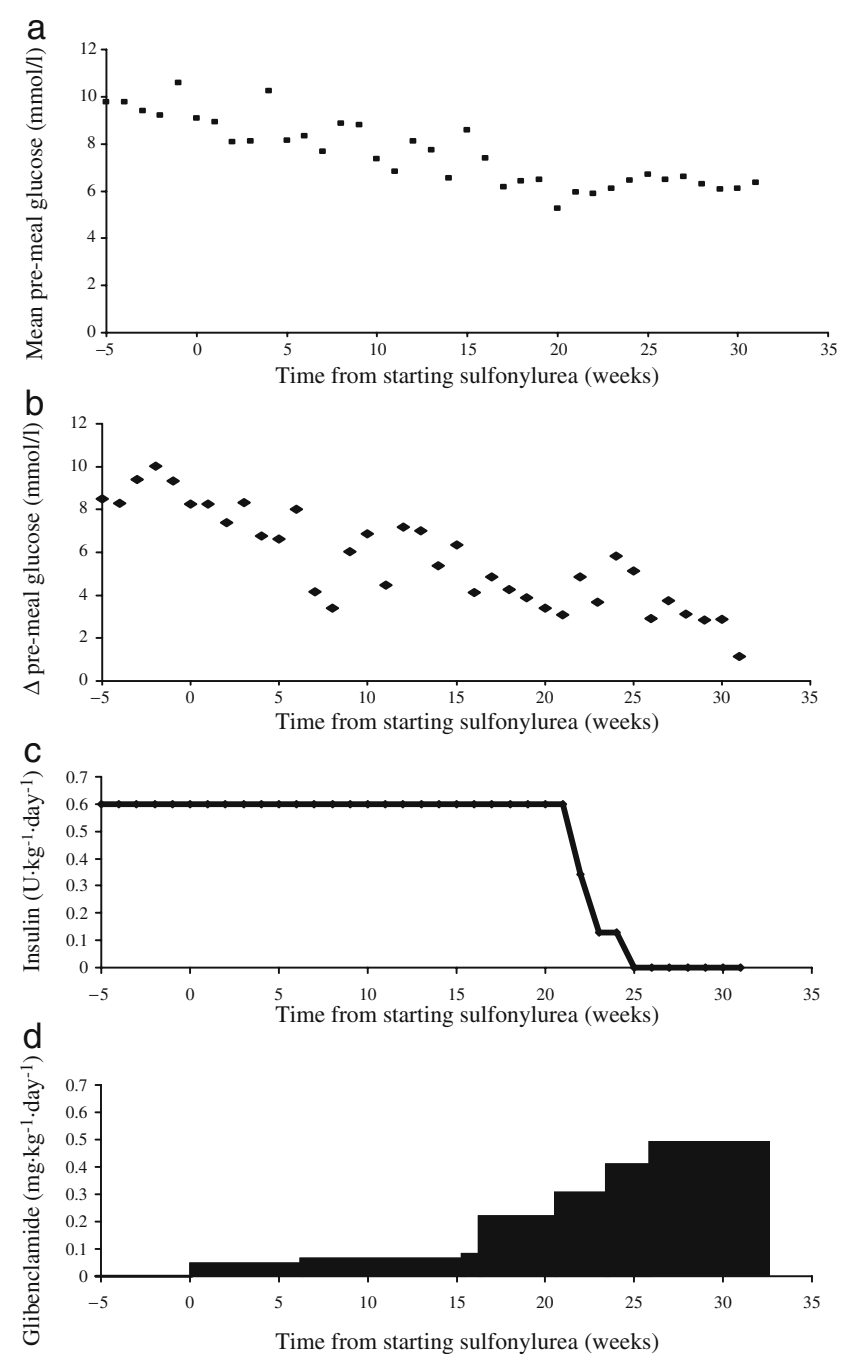

Fig. 1 Glucose homeostasis from 5 weeks before until 32 weeks after starting sulfonylurea treatment at age 23 months. All values are calculated for each week of treatment. a Mean daily pre-meal glucose values calculated each week. b Mean variability in daily pre-meal glucose values calculated each week with variability calculated as $\Delta$, i.e. the difference between the maximum glucose value and minimum glucose value on a given day. c Insulin dose. d Glibenclamide dose discontinued and remained low $(6.5,6.7,6.6,6.4$ and $6.4 \%$, mean $6.5 \%)$ compared with when on insulin alone $(6.8,7.1$ and $7.0 \%$, mean $7.0 \%$ ). There were no symptoms of hypoglycaemia and 2 months after stopping insulin a Minimed $24 \mathrm{~h}$ continuous subcutaneous glucose monitoring showed no values $<2.2 \mathrm{mmol} / \mathrm{l}$ and fewer than $1 \%$ of glucose values below $3.0 \mathrm{mmol} / \mathrm{l}$.

Two years and one month after insulin was stopped, near normal blood glucose measurements continued without hypoglycaemia. The dose of glibenclamide was gradually reduced with the most recent dose being $0.11 \mathrm{mg} \cdot \mathrm{kg}^{-1} \cdot \mathrm{day}^{-1}$.

Impact of treatment on developmental milestones and motor function The child showed improvements in neurodevelopmental function and glucose homeostasis when sulfonylurea therapy was introduced. One month after starting sulfonylurea, when still on the initial low dose $\left(0.025 \mathrm{mg} \cdot \mathrm{kg}^{-1} \cdot \mathrm{day}^{-1}\right)$, he showed marked improvement in gross motor function, changing from abdominal crawling and not standing unsupported to walking independently. Examination by a paediatrician at this time showed no hypotonia and markedly improved muscle power. This was later confirmed by a neurologist. He also started to include the pincer grasp in his repertoire of grasping movements. His language became bisyllabic and he showed more explorative behaviour. Retesting with the BSID II scales 4 months after starting glibenclamide confirmed he had markedly improved on motor function (Fig. 2). By 39 months he scored a functional age of 20 months, whereas results prior to sulfonylurea treatment suggested he would have reached a functional age of 12 months (Fig. 2). In contrast to motor function there was no clear evidence of improvement in mental function on BSID II scales. At 39 months, his functional age was 20 months for mental function, which was in line with results prior to the initiation of glibenclamide (Fig. 2).

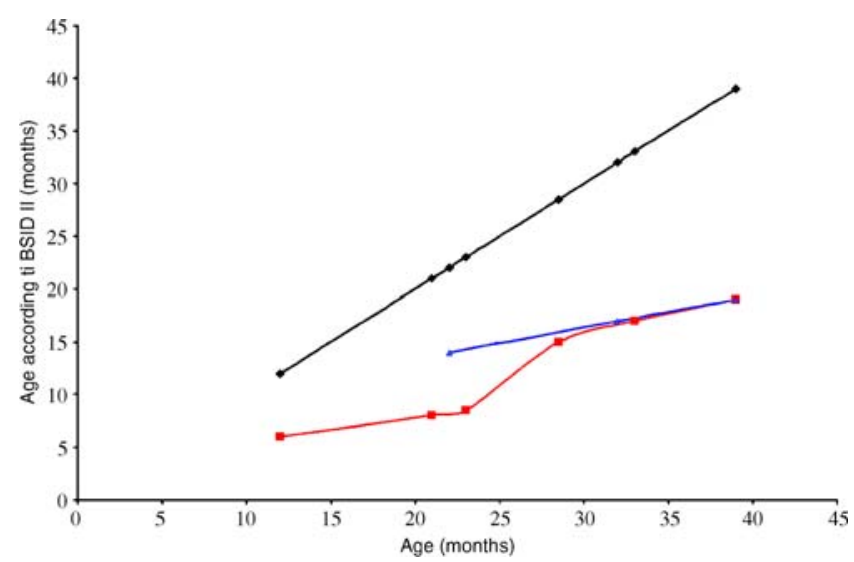

Fig. 2 Functional ages on BSID II scales according to actual age. The $45^{\circ}$ black line represents the reference (the expected functioning age for actual age as found in normal peers). The coloured lines represent the patient: red, psychomotor developmental index; blue, mental developmental index 
Just before his fourth birthday, the boy developed absences lasting 1-3 s and general concentration seemed diminished. Twenty-four-hour EEG monitoring showed multiple runs of multifocal spike waves, maximally over the frontal lobes with a frequency of 3-4 Hz. These seizures improved on treatment with a low dose of valproic acid $\left(10.7 \mathrm{mg} \cdot \mathrm{kg}^{-1} \cdot \mathrm{day}^{-1}\right)$.

\section{Discussion}

We report long-term treatment with glibenclamide in a patient with neonatal diabetes and neurological features associated with a KCNJ11 mutation. There was improved glycaemic control, which continued for over 2 years after insulin had been stopped, and a maintained improvement in motor development. This suggests sulfonylureas, by binding to the SUR subunit of the potassium channel, can close the $\mathrm{K}_{\mathrm{ATP}}$ channel $[5,13]$ and hence both increase insulin secretion and possibly improve neurological features.

The response of glycaemia This case confirms that patients with $K C N J 11$ mutations can achieve near normalisation of glucose control on sulfonylurea tablets alone [6-10], even if they have intermediate DEND syndrome. The fall in $\mathrm{HbA}_{1 \mathrm{c}}$ $(0.5 \%)$ was less marked than the changes in pre-meal glucose would suggest. Values could reflect either the small reduction in fasting glucose or that there was undetected hypoglycaemia when on insulin. The response to hypoglycaemia may be moderated by the Kir6.2 mutation. $\mathrm{K}_{\text {ATP }}$ channels are present in the glucose-sensing neurons of the ventromedial hypothalamus that play a key role in the central detection of hypoglycaemia and the initiation of protective counter-regulatory epinephrine (adrenaline) and glucagon responses [14-16]. There was undetected hypoglycaemia when on insulin in our patient but formal studies of the hypoglycaemia response in these patients are required. The reduction in hypoglycaemia after starting sulfonylurea treatment appeared to be a reduction in glycaemic fluctuations rather than increased awareness of hypoglycaemia.

We report excellent long-term glycaemic control on sulfonylurea after transfer from insulin for over 2 years, which considerably extends the previous longest report of 6 months [6]. Initially, discontinuation of insulin required high doses of glibenclamide $\left(0.4 \mathrm{mg} \cdot \mathrm{kg}^{-1} \cdot \mathrm{day}^{-1}\right)$ but with time doses have been able to be markedly reduced with the most recent dose being $0.11 \mathrm{mg} \cdot \mathrm{kg}^{-1} \cdot \mathrm{day}^{-1}$. The mechanism for this is unclear and contrasts with type 2 diabetes where increasing doses are usually required. This would suggest this might be a successful therapy over many years; in keeping with this, one patient who never received insulin has been successfully treated with sulfonylurea for 46 years [1]. Longer follow-up is required, as in type 2 diabetes secondary sulfonylurea failure typically occurs after 3 years $[17,18]$.
The response of neurological features The neurological features in patients with mutations in the KCNJ11 gene are probably due to altered function in the $\mathrm{K}_{\text {ATP }}$ channels in brain, nerve and muscle, as they are associated with specific mutations and cause a reproducible pattern of neurological features depending on the severity of the mutation $[3,4]$. Hypoglycaemia may also contribute to these neurological features but these cause a different spectrum and milder pattern of neurological defect [19] and would probably not be related to specific mutations.

This is the first report of an improvement in neurological status when starting sulfonylurea therapy. The greatest benefit was in motor function with an improvement in the muscle weakness rather than coordination suggesting a peripheral effect at either neuron (the SUR1 subunit) or muscle (the SUR2B subunit). As glibenclamide binds to both SUR1 and SUR2B, the benefit could have resulted from action on either receptor. It is not very likely that the improvement was coincidental as it was marked, coincided with starting the treatment and was maintained. It should be emphasised that this is a single case and confirmation of motor improvement requires careful study of further cases and longer follow-up. A deterioration in motor function if the patient returned to insulin therapy would have firmly established the link with the therapy but was considered unethical. It is interesting that neurological improvement was seen on a low dose of sulfonylurea that did not result in freedom from exogenous insulin. This suggests that the threshold for a neurological response may be different from that needed for a beta-cell response as predicted by Proks et al. [11]. A reduction in hypoglycaemia could also contribute to any neurological improvement and might explain the change in grasping behaviour and language [20, 21].

Glibenclamide treatment did not clearly improve mental function even though it binds to the SUR1 receptors that are present in the brain. A likely explanation is that it is unable to cross the blood-brain barrier in sufficient amounts. In animal studies, sulfonylureas do cross the blood-brain barrier but the brain:plasma ratio is much lower than in other tissues, principally because an active system transports the sulfonylurea out of the brain again [22]. We have been unable to find studies in man examining whether glibenclamide or other sulfonylurea cross the blood-brain barrier. An alternative explanation is that the loss of plasticity in brain development means that changes are irreversible if sulfonylurea treatment is started at 23 months. This would support early diagnosis of Kir6.2 mutations and early transfer to sulfonylurea medication.

The development of non-complex generalised seizures in our patient after transfer to sulfonylurea has not been described in any of the 12 patients with the V59M mutation, although ten patients of these have intermediate DEND syndrome [4]. It is unclear whether the absence 
seizures are primarily linked to the $K C N J 11$ gene mutation and represent an intermediate neurological phenotype between intermediate and full DEND syndrome. The multiple foci differ from the bilateral synchronous $3 \mathrm{~Hz}$ spike waves commonly seen in absence epilepsy with a genetic origin [23]. An alternative explanation is that it may be attributed to minor lesions of the brain originating from recurrent hypoglycaemia during early phases of life.

\section{Conclusion}

We conclude that improved glycaemic control with sulfonylurea treatment is not just a short-term phenomenon but can persist in the presence of reducing doses. Improvement of motor function coincided with glibenclamide introduction and might be consistent with improved $\mathrm{K}_{\mathrm{ATP}}$ channels in the peripheral neurons or muscle. This emphasises that all patients diagnosed with diabetes under the age of 6 months should be rapidly tested for Kir6.2 mutations and assessed for glycaemic control and neurological features both before and after transfer to sulfonylurea therapy. Future research is needed to evaluate the neurological response of patients with Kir6.2 mutations in response to different sulfonylureas.

Acknowledgements The authors wish to thank the patient and his family, and A. van Rhijn (Department of Paediatrics, Meander Medical Center, Amersfoort, the Netherlands), P. G. Barth (Department of Paediatric Neurology, Amsterdam University Medical Center, Amsterdam, the Netherlands), M. Rodenburg (Practice for Paediatric Physiotherapy, Vlaardingen, the Netherlands) and A. Hartman (Department of Paediatric Physiotherapy, Erasmus University Medical Center, Rotterdam, the Netherlands). This work was funded by the Wellcome Trust, ISPAD and the Child Health and Wellbeing Fund. A. T. Hattersley is a Wellcome Trust Research Leave Fellow.

Duality of interest There is no duality of interest.

\section{References}

1. Gloyn AL, Pearson ER, Antcliff JF et al (2004) Activating mutations in the gene encoding the ATP-sensitive potassiumchannel subunit Kir6.2 and permanent neonatal diabetes. N Engl J Med 350:1838-1849

2. Gloyn AL, Reimann F, Girard C et al (2005) Relapsing diabetes can result from moderately activating mutations in KCNJ11. Hum Mol Genet 14:925-934

3. Slingerland AS, Hattersley AT (2005) Mutations in the Kir6.2 subunit of the KATP channel and permanent neonatal diabetes: new insights and new treatment. Ann Med 37:186-195

4. Hattersley AT, Ashcroft FM (2005) Activating mutations in Kir6.2 and neonatal diabetes: new clinical syndromes, new scientific insights, and new therapy. Diabetes 54:2503-2513
5. Gribble FM, Reimann F (2003) Sulphonylurea action revisited: the post-cloning era. Diabetologia 46:875-891

6. Sagen JV, Raeder H, Hathout E et al (2004) Permanent neonatal diabetes due to mutations in KCNJ11 encoding Kir6.2: patient characteristics and initial response to sulfonylurea therapy. Diabetes 53:2713-2718

7. Klupa T, Edghill EL, Nazim J et al (2005) The identification of a $\mathrm{R} 201 \mathrm{H}$ mutation in KCNJ11, which encodes Kir6.2, and successful transfer to sustained-release sulphonylurea therapy in a subject with neonatal diabetes: evidence for heterogeneity of beta cell function among carriers of the R201H mutation. Diabetologia 48:1029-1031

8. Zung A, Glaser B, Nimri R, Zadik Z (2004) Glibenclamide treatment in permanent neonatal diabetes mellitus due to an activating mutation in Kir6.2. J Clin Endocrinol Metab 89: 5504-5507

9. Codner E, Flanagan S, Ellard S, Garcia H, Hattersley AT 2005 High-dose glibenclamide can replace insulin therapy despite transitory diarrhea in early-onset diabetes caused by a novel R201L Kir6.2 mutation. Diabetes Care 28:758-759

10. Colombo C, Delvecchio M, Zecchino C, Faienza MF, Cavallo L, Barbetti F (2005) Transient neonatal diabetes mellitus is associated with a recurrent (R201H) KCNJ11 (KIR6.2) mutation. Diabetologia 48:2439-2441

11. Proks P, Antcliff JF, Lippiat J, Gloyn AL, Hattersley AT, Ashcroft FM (2004) Molecular basis of Kir6.2 mutations associated with neonatal diabetes or neonatal diabetes plus neurological features. Proc Natl Acad Sci USA 101:17539-17544

12. Touwen BC (1976) Neurological development in infancy. Clinics in developmental medicine no. 58. London, William Heinemann Medical Books

13. Henquin JC (2000) Triggering and amplifying pathways of regulation of insulin secretion by glucose. Diabetes 49: $1751-1760$

14. Lee K, Dixon AK, Richardson PJ, Pinnock RD (1999) Glucosereceptive neurones in the rat ventromedial hypothalamus express KATP channels composed of Kir6.1 and SUR1 subunits. J Physiol 515:439-452

15. McCrimmon RJ, Evans ML, Fan X et al (2005) Activation of ATPsensitive $\mathrm{K}+$ channels in the ventromedial hypothalamus amplifies counterregulatory hormone responses to hypoglycemia in normal and recurrently hypoglycemic rats. Diabetes 54:3169-3174

16. Evans ML, McCrimmon RJ, Flanagan DE et al 2004 Hypothalamic ATP-sensitive $\mathrm{K}+$ channels play a key role in sensing hypoglycemia and triggering counterregulatory epinephrine and glucagon responses. Diabetes 53:2542-2551

17. Matthews DR, Cull CA, Stratton IM, Holman RR, Turner RC 1998 UKPDS 26: sulphonylurea failure in non-insulin-dependent diabetic patients over six years. UK Prospective Diabetes Study (UKPDS) Group. Diabet Med 15:297-303

18. Ball AJ, McCluskey JT, Flatt PR, McClenaghan NH (2004) Chronic exposure to tolbutamide and glibenclamide impairs insulin secretion but not transcription of K(ATP) channel components. Pharmacol Res 50:41-46

19. Warren RE, Frier BM (2005) Hypoglycaemia and cognitive function. Diabetes Obes Metab 7:493-503

20. Flykanaka-Gantenbein C 2004 Hypoglycemia in childhood: longterm effects. Pediatr Endocrinol Rev 1 [Suppl 3]:530-536

21. Ryan CM, Becker DJ (1999) Hypoglycemia in children with type 1 diabetes mellitus. Risk factors, cognitive function, and management. Endocrinol Metab Clin North Am 28:883-900

22. Takanaga H, Murakami H, Koyabu N et al 1998 Efflux transport of tolbutamide across the blood-brain barrier. J Pharm Pharmacol 50:1027-1033

23. Cowan LD 2002 The epidemiology of the epilepsies in children. Ment Retard Dev Disabil Res Rev 8:171-181 